\title{
New Genealogy: It's Not Just for Kinship Anymore
}

\author{
ROBERT J. QUINLAN \\ EDWARD H. HAGEN \\ Washington State University
}

\begin{abstract}
Genealogy has been a pillar of anthropological research since the earliest ethnographic fieldwork. A turn toward demographically and quantitatively oriented kinship studies in the 1960s highlighted the need for more systematic genealogical methods. New computer-assisted, iterative field methods were developed in response. These methods can dramatically improve data quality and quantity and are remarkably flexible. Here, the authors outline an iterative genealogical approach that has been used to study kinship, migration, education, alcoholism, food sharing, intragroup aggression, father absence, community fissioning, and land ownership. The authors demonstrate the reliability of these data and show how they can be analyzed. The unobtrusive genealogical methods outlined here could be used to study terminologies and cognitive models of kinship; however, the authors focus on applications to demography, epidemiology, and economics.
\end{abstract}

Keywords: demography; epidemiology; population structure; quantitative methods; scientific ethnography

\section{INTRODUCTION}

G renealogies are historically important in anthropology (Rivers 1900). Several classic texts offer good, practical advice in collecting genealogies, particularly focusing on kin terminologies (Schusky 1983:53-55; Barnard and Good 1984:26-33). There have been updated and more detailed approaches (e.g., Chagnon and Bryant 1984), yet these methods tend to be overlooked, and recent anthropological methods "bibles" (Bernard 1998,

Thank you, Marsha Quinlan, for help developing these field methods and for advice on an earlier version of this article. Thank you, Shane Macfarlan, for help collecting land use data in the summer of 2006. Thank you, Russ Bernard and three anonymous reviewers, for excellent advice for developing this article. Thank you, Mark Flinn, for encouraging this line of research and for sharing your early census data. Most especially, thank you to the people of Bwa Mawego, who have so enthusiastically embraced this genealogical work and so generously offered their time and attention to help us understand their community.

Field Methods, Vol. 20, No. 2, May 2008 129-154

DOI: $10.1177 / 1525822 X 07314034$

(C) 2008 Sage Publications 
2002; de Munck and Sobo 1998) give scant coverage to genealogical interviewing. Here, we fill a large gap by describing the method and potential of a computer-assisted approach to genealogical interviewing useful in kinship analysis and other areas, including economic and biocultural anthropology, human ecology, demography, and genetic epidemiology. There are two objectives: The first is to outline an iterative, computer-assisted process of collecting accurate genealogical data. The second is to extend the method of genealogical interviewing to collect data for other domains by using a genealogical database as a foundation.

Dissatisfaction with traditional kinship studies arose in mid-twentieth-century anthropology (e.g., Schneider and Homans 1955). Many anthropologists turned to cognitive approaches focusing on kinship terminologies (DuMont 1953; Romney and Epling 1958; Goodenough 1967). Others focused on demographic issues in kinship: How does kinship play out "on the ground" quantitatively (e.g., Riviere 1969; Hammel 1976; Chagnon 1979)? We describe techniques extending demographic approaches to kinship analysis in which Napoleon Chagnon (1974) began developing a computerized method in the early 1970s. We outline a computer-assisted approach for collecting genealogies and propose extending the use of genealogical interviews as a generalized tool for ethnography and biocultural anthropology. In this approach, genealogies provide an etic map of social relationships that can aid understanding of social structure, inheritance patterns, relations among neighbors, and so forth. Furthermore, the etic genealogy can be used to understand emic models of kinship and terminologies. The focus here, however, is on the demographic, economic, and epidemiological applications of genealogical methods.

Genealogical interviews are broadly useful: Traditionally, genealogies provide a window on kin structure, marriage patterns, and descent. We can use genealogical interviews to check the accuracy of informants and our own informal impressions (Rivers 1910). Conflicts between two genealogical accounts can give important information about local politics (Bohannan 1952) and other conflicts of interest (Chagnon 2000). Importantly, extensive genealogical knowledge also gives the ethnographer some veracity as a quasi member of the community-who else could know so much about local families (see Cronk 2004:8-11)? Finally, genealogies can make sampling moot, because in many cases, the data set can include the entire community. 


\section{ITERATIVE GENEALOGICAL METHOD}

\section{The Census}

Rivers's (1910) guidelines for collecting genealogies are still useful, and Barnard and Good (1984:26-33) suggest some additional considerations following Rivers (1910) and Barnes (1967). The new genealogical approach shares the same basic features of Rivers's method, but offers much more. The approach begins with a census of a community: in this case, Bwa Mawego, Dominica, West Indies. Mark Flinn conducted an initial census of Bwa Mawego in 1987, and Rob Quinlan (hereafter, RQ) updated the census in 1998. Both censuses included the name, date of birth, and names of parents for each individual in each household in the study community. This information served as the foundation for the genealogical database RQ constructed over multiple field trips beginning in 1993. RQ entered the census data into a database with the format shown in Table 1.

Here, "9999" indicates missing data. "Name" was recorded as "LastFirst"; "maiden" is a woman's maiden name if married; "hse\#" is an identification number for the household; "id\#" is an identification number for each ego; "dob" is date of birth; "mid\#" and "fid\#" are mother's and father's ego identification numbers, respectively; and "alive" indicates whether the person was living at the time of the census, where $1=$ alive, $0=$ dead, and "dod" indicates date of death. Notice that "StewartSarah" and "StewartMicha" appear twice in the census: they were entered once as parents of "StewartJonathan" and once for the visit to their own household. At this first step, these double entries are common. We were able to avoid double entries for StewartRoger's parents because they lived in the same household.

\section{Software Identifies Gaps and Errors}

We needed a way of identifying double entries and gaps in the data. Initially, RQ used the KINDEMCOM computer program developed by Chagnon and Bryant (1984) to "diagnose" the data. KINDEMCOM is now difficult to obtain, but Hagen's (n.d.) Descent software is an updated and expanded version of KINDEMCOM, which is open source and freely available online (see Hagen [n.d.] for the URL). Both programs look through the data and identify problems that need to be corrected. Descent should be able to open any text-based, flat-file database (i.e., a tab- or comma-delimited file). Once key variables — ego, sex, mother, father, living/dead — have been mapped to the appropriate columns through drop-down menus in the "editor" view, Descent does a simple error check. (The software interface 
TABLE I

Layout of Genealogical Data in the Initial Working Database

\begin{tabular}{|c|c|c|c|c|c|c|c|c|}
\hline name & maiden & hse\# & id\# & dob & mid\# & fid\# & alive & dod \\
\hline StewartRoger & & 15 & 123 & $12 / 21 / 1970$ & 56 & 112 & 1 & \\
\hline SmithMargaret & & 15 & 56 & $9 / 15 / 1955$ & 50 & 51 & 1 & \\
\hline StewartJonathan & & 15 & 112 & $6 / 6 / 1953$ & 101 & 99 & 1 & \\
\hline SmithEdith & Jones & 15 & 50 & $5 / 5 / 1922$ & 505 & 506 & 1 & \\
\hline SmithPhilsbert & & 9999 & 51 & about 1920 & & & 0 & 1980 \\
\hline StewartSarah & & 9999 & 101 & Jan. 1931 & & & 1 & \\
\hline StewartMicha & & 9999 & 99 & 1926 & & & 1 & \\
\hline JonesAreatha & Charles & 9999 & 505 & Feb. 1896 & & & 0 & 1961 \\
\hline JonesEdmund & & 9999 & 506 & about 1890 & & & 0 & \\
\hline StewartSarah & Philomen & 27 & 101 & $1 / 12 / 1931$ & 98 & 97 & 1 & \\
\hline StewartMicha & & 27 & 99 & $10 / 16 / 1926$ & 95 & 94 & 1 & \\
\hline PhilomenMarie & & 9999 & 98 & May 1911 & & & 0 & 1979 \\
\hline PhilomenRonnie & & 9999 & 97 & Mar. 1900 & & & 0 & 1973 \\
\hline StewartMelissa & McField & 9999 & 95 & about 1895 & & & 0 & \\
\hline StewartGeorge & & 9999 & 94 & about 1885 & & & 0 & \\
\hline
\end{tabular}

NOTE: These are fictitious data for illustrative purposes. Notice that italicized entries "StewartSarah" and "StewartMicha" appear twice in the census: they were entered once as parents of "StewartJonathan" and once for the visit to their own household. Double entries are common in the early phases of expanding a genealogy. Software identifies double entries and other "errors." Hse\# = household ID number; 9999 = missing data; id\# = ego ID number; dob = date of birth; mid\# = mother's ID number; fid\# = father's ID number; alive = whether ego is still living; dod = date of death.

is user friendly in that it allows the flat-file database to be set up in any manner the user chooses, at least with respect to the column positions, separation character, order, characters per field, names of variables, etc.) The output of the error check is displayed in a window that includes basic population statistics (number of living males and females and sex ratio), a list of errors, and a list of warnings. Fatal errors include duplicate ego ID codes, female fathers, male mothers, and undefined codes in the sex and living/dead columns. Nonfatal warnings include parents that do not appear as egos in the data file and (optionally) incest between first-degree relatives (a rare occurrence that might indicate a coding error). Simple edits to correct errors can easily be made within Descent.

In the second round of interviews, RQ employed five sources for genealogical information. Three sources were middle-aged couples (50-65) and their grown children. Two other sources were middle-aged men (45-55). All the sources were lifelong residents of Bwa Mawego. Each source was interviewed about each of the missing parents' names. There was usually 
considerable overlap in the data the sources provided, which permitted extensive cross-checking. At this point in the process, cross-checks were not used to establish formal quantitative reliability (discussed below). RQ followed up on discrepancies between sources, however, until he was confident that the problem was corrected. Once the missing parents' names were collected, the software generated a new list of missing parents' names, and RQ conducted a third round of interviews. The process was repeated until the informants were not able to remember any of the remaining parents' names. From there, the lineal kin were contacted concerning the missing names of their ancestors. Sometimes lineal kin could remember the names of ancestors; often they could not. Then the revised genealogy was run through the software and the entire process was repeated until all the errors were corrected. When the software generated a new error file, RQ conducted a series of interviews to clarify the discrepancy either with the sources or with kin for the questionable entry.

The software cannot identify one type of error: When an individual's name has two alternate spellings (or perhaps a nickname), he or she can appear in the genealogical file more than once. This error often reveals itself as the depth of the genealogy increases when the parents of ego are identified. Then two alternative names or spellings show up as siblings with the same birth date and who may be recorded as having children with the same mate. In other cases, duplicates with alternate spellings do not reveal themselves until the next step of the process: the sibling interview.

\section{The Sibling Interview}

For the sibling interview, we simply took the genealogical database and created two files: one sorted by mid\# and the other sorted by fid\# (Table 2). RQ returned to the sources, identified each sibling set, and queried the sources about any missing siblings and their whereabouts. At this point in the process, we also made queries about any childless individuals to see if any children had been overlooked. Duplicate entries with spelling variants or nicknames were also identified. For example, the sibling interview could find a person entered twice, once as "Tibroda" and once as "Philip." Often, the sibling interview identified other questionable entries. We highly recommend putting off the sibling interview until one is satisfied with the depth of the offspring to parent links; otherwise, the sibling interview will have to be repeated as more parents are identified.

We also used a variant of the sibling interview to reconstruct household composition. RQ has been monitoring household composition through a combination of census updates, direct observation during home visits, and 
TABLE 2

Example of Sibling File Sorted by Mother (names are fictitious)

\begin{tabular}{|c|c|c|c|c|c|c|c|}
\hline name & id\# & dob & dod & dead & $\operatorname{sex}$ & fid\# & mid\# \\
\hline LhommeAlton & 77 & $7 / 27 / 1966$ & & 0 & 1 & 84 & 87 \\
\hline LhommeAnthony & 78 & $5 / 7 / 1959$ & $12 / 21 / 1997$ & 1 & 1 & 84 & 87 \\
\hline LhommeJulia & 85 & $7 / 23 / 1970$ & & 0 & 0 & 84 & 87 \\
\hline LhommeJulius & 86 & $6 / 21 / 1969$ & & 0 & 1 & 84 & 87 \\
\hline LhommeMathias & 88 & $1 / 10 / 1962$ & & 0 & 0 & 84 & 87 \\
\hline LhommeMitchel & 89 & $4 / 30 / 1960$ & & 0 & 1 & 84 & 87 \\
\hline LhommePaulina & 92 & $10 / 16 / 1975$ & & 0 & 0 & 84 & 87 \\
\hline LhommeSoloman & 93 & $11 / 20 / 1964$ & & 0 & 1 & 84 & 87 \\
\hline LhommeStephen & 96 & $5 / 27 / 1965$ & & 0 & 1 & 84 & 87 \\
\hline StewartClovia & 319 & $10 / 17 / 1955$ & & 0 & 0 & 470 & 87 \\
\hline TellfordCaroline & 112 & $7 / 13 / 1970$ & & 0 & 0 & 115 & 118 \\
\hline TellfordClayton & 113 & 4/4/1967 & & 0 & 1 & 115 & 118 \\
\hline TellfordNicholson & 119 & 9/10/1971 & & 0 & 1 & 115 & 118 \\
\hline TellfordVioletMary & 120 & $9 / 19 / 1968$ & & 0 & 0 & 115 & 118 \\
\hline
\end{tabular}

NOTE: id\# = ego ID number; dob = date of birth; dod = date of death; dead $=$ whether ego is dead; sex $=$ sex of ego $(1=$ male, $0=$ female $)$ fid $\#=$ father's ID number; mid\# = mother's ID number.

informal interviews, but this multimethod approach has been limited to household composition since 1993. During the mother portion of the sibling interview, RQ asked informants to recall any other regular members of the mother's and sibling set's household. These individuals were recorded by name and kin relation to the sibling set in a "notes" column on the data sheets. The information could then be cross-checked with informal interviews with members of the sibling sets. These household interviews could be very useful in identifying cases of adoption or polygyny.

\section{Supplemental Information}

Following these steps, the resulting genealogical database contained good information for 1,826 individuals born between 1835 and 2004. At this point, data for villagers born after 1916 are complete and accurate, and data for villagers born after about 1880 are useful for many purposes; however, some caveats are in order: These data are useful for relatedness and number of surviving offspring. Results for grand-offspring may be questionable because of migration. The genealogical data by themselves are not useful for fertility (live births) or mortality. However, with supplemental information from censuses and other records, a genealogy can form the foundation of a useful demographic data set, provided that one restricts the 
analyses to a time period for which accurate information is available and cross-checked. We were lucky to have access to local church records, which allowed us to identify about another 1,200 people who either died young or whose lineage is no longer represented in Bwa Mawego. The missing individuals include many infants who died, often in the first few days or weeks of life, especially in the first half of the twentieth century. Also, church records were useful to identify individuals who left the village long ago (before about 1920).

Keeping up with the population is an ongoing task. When RQ returns to Bwa Mawego (once or twice a year), one of his first activities is to update the census. Several local friends keep track of births, deaths, and migrations from and back to the village for us.

\section{Informal Interviews}

The formal interviewing and data-cleaning processes outlined above are perhaps two-thirds of the picture. After we began working with these data, it was hard not to think about them all the time. Once the locals understood that we were interested in genealogy and family history, they often steered conversations in that direction. Also, in contrast to industrial nations, kinship is still a very important organizing principle in many developing populations, especially in rural areas. Information about kinship emerges frequently in the course of daily life. Informal interviews and observations can be very important, often leading to new insights or filling data gaps. "Jottings" (Bernard 2002:367-9) are especially important for this kind of serendipitous data collection. Later, we try to cross-check informally gathered information in genealogical interviews. Conversely, RQ often uses informal interviews to fill in gaps and cross-check other information. Likewise, the informants and anthropologist often take time to explore issues informally that come up in the monotonous genealogical interviews.

\section{Now You Have Some Useful Data}

Data extraction is surprisingly straightforward with the help of Hagen's (n.d.) Descent software. In addition to the error reports, the software produces eight other broad types of useful statistics:

1. Descent calculates a matrix of relatedness between each ego and everyone else, which is based on the coefficient of relatedness. In addition, it calculates " $\mathrm{F}_{\mathrm{g}}$ all" (the average relatedness of an individual to the entire population), " $\mathrm{F}_{\mathrm{g}} \mathrm{con}$ " (the average relatedness of an individual to his or her consanguineous kin), and the number of relatives in the population, which are all available as new variables for further analysis by Descent or can be saved to 
files. Descent is written in an interpreted scripting language called Python, which is not compiled, so calculating relatedness for a large genealogy $(1,000+$ egos) can take hours even on a fast desktop computer-plan ahead.

2. Descent identifies the founders of each lineage in the population. This information may be useful for studying territorial expansion, settlement patterns, genetic founder effects, and so forth.

3. The software also identifies each matrilineage and patrilineage and saves the lineage identification numbers as new variables indicating to which lineages each ego belongs. We have found these data to be particularly useful in studying differences between emically recognized patrilineages and informal, emically unrecognized matrilineages discussed later.

4. The "kin counter" function in Descent can be particularly useful. It allows the researcher to specify a type of kin relationship (e.g., MBS [mother's brother's son]) and then returns the number of kin in that category for each ego. The kin counter can calculate numbers of kin in "compound categories" of up to four links (FZDD [father's sister's daughter's daughter], MMZS [mother's mother's sister's son], etc.). Such data might be particularly useful in studies of complex categorical kin relations. The kin counter can also calculate the number of "mates" based on shared offspring, but whether they are concurrent or consecutive must be determined by the user. Determining whether a relationship is truly polygynous or a case of serial monogamy could be done by comparing dates of birth for children resulting from the union and by examining residence patterns (household and compound identifiers could be used). If polygyny is common or permitted in the particular population in question, then it would be advisable for the researcher to identify polygynous individuals by adding a variable (column) to the working database (see Table 1). Likewise, Descent can identify step-siblings, but determining whether they are coresident requires coding additional variables in the working database. A simple household identifier as shown in Table 1 should be sufficient for individuals who are still children. Otherwise, coresident egos can be identified in the sibling interviews. The flexible nature of the data input for Descent allows the kin counter to be used in many other imaginative ways. One could, for example, code biological and social parents in different fields. Then, the drop-down menus could use either biological or social parents for the mother and father ID. The kin counter could identify adoptive children as well as biological children. One could also use the "living" drop-down menu to code many interesting group-level relations. For example, one could code geographical areas in the data file and then enter those codes as "living" in the living/dead drop-down menus. The kin counter function would then return the numbers of kin in particular categories that live within a specified geographic region (e.g., within a hamlet or district). These are just a few possibilities.

5. Descent also calculates relationships between individuals and draws kinship diagrams. The "kin" function can identify all the individuals in an egocentric kindred, their kin connections to ego (e.g., FBSS [father's brother's son's son]), and their coefficients of relatedness. The kin function also draws egocentric diagrams up to four generations deep that are exported in both bitmap and postscript formats (the latter suitable for publication). 
6. The "group" function in Descent may also be quite useful. This function allows the user to specify a group (e.g., household, compound, village, or lineage), and the software calculates group size and the average relatedness within that group. Using the group function is simply a matter of including group identifiers as variables (columns) in the data set. A drop-down menu then allows the user to choose the variable to use as the group identifier.

7. Histograms and simple barplots of computed statistics and numeric variables can be plotted, as can scatterplots of any two variables (e.g., inbreeding coefficient vs. number of relatives).

8. Descent conducts principal components analysis and can display the results in 2D and 3D plots, which may help characterize the structure of kin groups. Much of this raw data produced by the various Descent modules can be further transformed into other useful variables, as described later.

Finally, Descent is completely free and open source, so users with some computer programming ability can add functions. For easy extensibility and portability, it is written in the cross-platform scripting language Python and uses the cross-platform graphical user interface toolkit wxPython (based on wxWidgets). Although currently an installer is only available for Windows, a MacOS X version is up and running and will be available shortly. A Linux version is also possible.

Even sparse genealogical data can yield accurate estimates of relatedness. Complete and clean linkages from offspring to parents going back as far as possible (usually four or five generations for Bwa Mawego) are sufficient and not difficult to collect. Such data allow estimates of coefficients of relatedness (average proportion of alleles shared by two individuals), inbreeding, or genealogical relationships such as MBD (mother's brother's daughter), and so forth.

"Extra-pair copulation" (EPC) could pose a reliability problem for relatedness. Our sources identified several suspected cases where the putative father of a child may not have been the biological father. Extensive crosschecking using multiple sources in the early phases of data collection is particularly important for identifying potential cases of "misassigned" paternity. For those cases, we could weight relatedness based on reduced paternity certainty. For many purposes, biological kinship may not be especially important. For other cases, some reduced reliability in relatedness may be tolerable. However, a warning is in order: EPC rates probably vary considerably across human populations. Field anthropologists should decide whether biological paternity is important for their research. If it is, then cross-checks, additional interviews, or analyses of genetic markers may be necessary to identify misassigned paternity.

Descent has some other important limitations. It cannot identify marriages/ conjugal unions that do not result in offspring. This has not been an important 
point for the Caribbean research discussed below because conjugal relationships are largely defined by progeny. However, nonreproductive conjugal relationships could be coded into the data file with start and end dates; these data could then be analyzed with a standard statistical package.

\section{BEYOND KINSHIP: EXTENDING THE SCOPE OF GENEALOGICAL INTERVIEWS}

Much of the iterated genealogical interviewing described so far took place between 1997 and 2006. During that time, RQ developed particularly close relationships with two sources: One source is an older couple (now in their 70s and 80s) and their grown granddaughter. The other is a middleaged couple (now in their 60s) and two of their grown daughters. In a sense, these sources and RQ trained each other. They taught RQ how to ask questions appropriately and unambiguously, and RQ taught them how to "power through" really boring paperwork. This makes for an extremely efficient data-gathering relationship.

The format of the genealogical interviews was useful for other systematic data collection. The genealogy file serves as a roster of the village, which allows us to explore other information without having to conduct surveys of the entire population. In our experience, questionnaires and surveys yield very poor-quality data in this community, even for basic information such as household composition. Villagers do not trust door-to-door data collection and have an almost complete lack of patience for such intrusions. Furthermore, it is almost impossible to set up an appointment with most families. Surveying simply does not fit the culture.

In 2004, RQ became interested in gender differences in education, migration, and alcohol use in Bwa Mawego. We could have constructed a house-to-house survey or recruited a sample from the village to participate in structured interviews. Instead, in the summer of 2005, we decided to explore the strengths of the genealogical interview. We conducted a simple interview with two sources (the family groups discussed above). At the outset, the informants, Marsha Quinlan, and RQ discussed the nature of the interview and the purpose for collecting the data. We assured our informants that we would, as usual, protect their privacy and the privacy of the individual villagers we would discuss. We limited queries to living residents and recently dead individuals who were at least 18 years old in 2005. All interviews were conducted in Dominican Creole English (Roberts 1988: 97-99).

We started by asking whether the villager still lived in Bwa Mawego; if not, we asked where he/she was now. If the villager was still a resident, we 
followed up by asking if he or she had ever attended high school, whether he/she was "drinking plenty," and whether he or she was relatively poor. The group nature of these interviews was beneficial: Sometimes, one member of the group would disagree with the information that another gave for one of the individuals in the genealogy. We followed up disagreements with discussions that helped to clarify the response. We discuss these interviews, their reliability, and uses in more detail below.

\section{CASE STUDY: BWA MAWEGO, COMMONWEALTH OF DOMINICA, WEST INDIES}

The Commonwealth of Dominica is a small, rural island nation located between Guadeloupe and Martinique $\left(15^{\circ} \mathrm{N}, 61^{\circ} \mathrm{W}\right)$. The island is mountainous and relatively undeveloped. Dominica's population (approximately 62,000) is of mixed African, European, and Island-Carib descent. Most Dominicans are bilingual in English Creole and French Patois.

Bwa Mawego is one of the least developed villages on the remote windward side of the island. There are about 600 full- and part-time residents, occupying small (150-600 $\mathrm{ft}^{2}$ ), mostly one- or two-room houses. (As of July 2007, 408 people lived in Bwa Mawego.) Average annual household income in Bwa Mawego is approximately EC $\$ 5,000$. (US\$1,850). Economic activities include subsistence horticulture, fishing, bay oil production, banana production, running a rum shop, and limited wage labor. Opportunities for education are limited. About 30\% of villagers born between 1955 and 1986 have attended "high school," which is approximately equivalent to ninth and tenth grade in the United States. Almost no older individuals attended high school because it was largely unavailable before the mid-1970s.

The population is relatively healthy. Children's mean height and weight for age are near the 50th percentile of U.S. growth standards (Flinn, Leone, and Quinlan 1999). Infant mortality rate is relatively low for the Caribbean region. Life expectancy for Dominicans is high compared to other Caribbean nations. ${ }^{1}$

Kinship and family are the foundations of economic, social, and reproductive behavior in Bwa Mawego. Almost everyone in the village is related through blood or marriage. Kin ties provide a map for navigating social life and offer avenues for the flow of goods and services. Households have fuzzy boundaries in terms of composition, and classification schemes are of limited use in this community (e.g., Goodenough 1955). Many households have a matrifocal orientation and consist of several women and their children. Even a male-headed household can be matrifocal if it also includes 
several women at its core (e.g., Smith 1996:39-57). Along with matrifocal families, conjugal families, single-mother families, and various alternative styles are common (Quinlan and Flinn 2003). Often, several households of closely related kin are grouped together in a family compound. Beyond households, larger kin groups are important (see Quinlan and Flinn 2005). There are several large patrilineages and many more small lineages. Matrilineages are not recognized. Patrilineal descent provides individuals with access to ancestral family lands, which can be advantageous to individuals whose immediate family does not own land. The importance of patrilineages in a largely matrifocal context reflects the many paradoxes inherent in rural Caribbean culture.

\section{Structure of Lineages and Reproduction}

The most straightforward application of genealogical interviews is in kinship research. We used a sample of 130 males and 124 females born between 1900 and 1955 to examine sex-specific effects of kinship on number of offspring and grand-offspring (only results for number of offspring are presented below) (see Quinlan and Flinn 2005). Individuals who emigrated or who have unknown parents were excluded from the analyses. One important objective was to examine the effect of norms for lineal social organization on reproduction. In Bwa Mawego, patrilineages are emically recognized, but matrilineages are not. Comparing the effects of matri- and patrilineage on individual reproduction, therefore, allows us to explore the importance of cultural models for kinship.

Variables were extracted from the genealogical database using Descent software (Hagen n.d.). We measured reproductive success (RS) as number of surviving offspring. Lineage variables included sex ratio of matri- and patrilineages and the number of matri- and patrilineal kin residing in the village. Sex ratio is the number of lineage males resident in the village divided by the total number of resident lineage members. Descent does not calculate sex ratios of groups, but it was relatively simple to determine using SPSS: We coded male $=1$ and female $=0$; then, we calculated the mean for "sex" (the proportion of males) by lineage, which was saved as a new file and merged with the original file using lineage ID numbers as the key variable. Sex ratio was used rather than numbers of males and females in the kin group because the latter caused substantial multicollinearity (the number of males in the lineage is highly correlated with number of females). Kindred variables include sex ratio of the kindred and total number of nonlineal relatives residing in the community. Calculating the kindred sex ratio is more complicated than calculating lineage sex ratio. 
There are several ways this could be done: Using Descent, one could create a new variable in which all dead individuals, nonresident individuals, and females are coded in a single category. Then, this variable would be designated as the "living" variable using the drop-down menus in the Descent data editor. Descent's "relatedness" function will then return the number of male relatives living in the community. For a smaller kindred, one can simply use the kin counter function to count the numbers of male and female relatives in various categories of interest. Number of nonlineal relatives was used instead of total number of relatives because the latter variable caused substantial multicollinearity when included in models with matri- and patrilineage sizes. Calculating the number of nonlineal relatives is straightforward: We simply subtracted the number of lineal relatives from the total number of relatives. Mother, father, and number of brothers and sister residing in the community were entered in the models to test whether kindred and lineage effects were mediated by immediate family.

Multiple linear regression modeled effects of kindred, lineage, and immediate family characteristics on RS. The analysis is in four steps: Year of birth was entered on the first step to control for secular trends in fertility. The second step examines the effect of kindred variables. The third step includes matri- and patrilineage variables. And the fourth step includes mother, father, and number of brothers and sisters. At each step, quadratic terms were entered for each predictor and significant terms $(p \leq .10)$ were retained in the models.

Results for structure of lineages. Lineage characteristics were more strongly associated with RS than were kindred characteristics, and sex differences in kinship effects were apparent. Initially, only matrilineage characteristics showed significant effects on male RS: female-biased sex ratio and moderate size matrilineage tended to increase male RS. However, the sex ratio effect was mediated by numbers of brothers. In the final model, RS was a quadratic function of matri- and patrilineage size: A matrilineage with about thirty-two members $\left(\right.$ beta $_{\mathrm{x}}=.192, p=.024$ beta $_{\mathrm{x}}{ }^{2}=-.003, p=.029$ ) and a patrilineage with about seventy-three members $\left(\right.$ beta $_{\mathrm{x}}=.135, p=.071$; beta $_{\mathrm{x}}{ }^{2}=-.001$, $p=.093$ ) in the village tended to maximize male RS, which decreased in larger lineages (Figure 1). Number of brothers in the community was negatively associated with men's RS (beta $=-.636, p=.034$ ), suggesting competition for resources among males over the life course. Number of sisters and presence of mother and father in the village were not significant predictors of men's RS. When immediate family variables were included in the model, male-biased kindred sex ratio was positively associated with RS, but the effect was only marginally significant $(p=.092){ }^{2}$ Together, these 
FIGURE I

Effects of Lineage Size on RS (combined data for men and women)

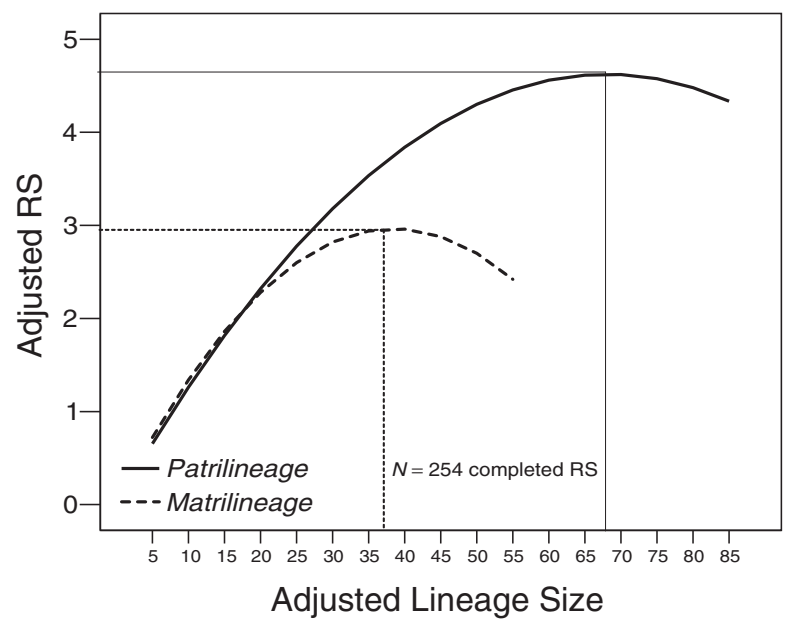

NOTE: $\mathrm{RS}=$ reproductive success.

results indicate substantially higher fitness among men from moderately large matrilineages, large patrilineages, and those who have few brothers.

For women, matrilineage sex ratio and patrilineage size were associated with RS, but patrilineage sex ratio and matrilineage size were not. Initially, women's reproduction was associated with kindred size and sex ratio, but the relations were mediated when lineage variables entered the model. Women's RS was positively associated with male-biased matrilineage sex ratio (beta $=6.370, p=.006$ ) and was a quadratic function of patrilineage size $\left(\right.$ beta $_{\mathrm{x}}=.132, p=.021$; beta $\left._{\mathrm{x}}{ }^{2}=-.001, p=.031\right)$. A patrilineage with about sixty-three members residing in Bwa Mawego tended to maximize RS. Number of siblings and presence of parents were not associated with women's RS (Figure 1).

\section{Father Absence and Conjugal Stability}

Genealogical data can be used to study other aspects of mating and family composition. We used genealogical data to test predictions concerning the intergenerational transmission of conjugal stability (Quinlan and Flinn 2003). The sample consists of 803 individuals for whom complete genealogies are available as of 1999. 
Formal marriage in Bwa Mawego is an institution in decline, but many villagers still forge durable conjugal unions. In Bwa Mawego, as elsewhere in the Caribbean, a couple commonly has a child together before deciding to establish a conjugal household. Once established, conjugal households are usually stable. Currently, about $30 \%$ of mothers are in long-term unions. This compares to about $36 \%$ for Antigua, $49 \%$ for Barbados, $55 \%$ for Jamaica, $29 \%$ for St. Kitts, $45 \%$ for St. Lucia, and 38\% for St. Vincent (Roopnarine et al. 2005).

Two proxy measures of conjugal stability were used for this analysis: (1) father-absence status and (2) number of mates with whom individuals had children. Ego's father-absence status (i.e., whether ego spent their early childhood with their father) was determined from genealogies using one of two methods. If an individual's mother was known but father was unknown (i.e., "not from here"), then that ego was designated "father absent." Remaining individuals were grouped according to their mothers' identification number. Then, egos within groups of maternally related siblings were compared according to their fathers' identification numbers. If an ego's mother and father had only one child together and ego's mother had other children, then ego was designated father absent. Genealogical determination of fatherabsence status of living residents of Bwa Mawego was cross-checked using informal interviews and census data. Cross-checks determined that the genealogical method for assigning father absence/presence is reliable. Of 147 living individuals whose life histories are well known to us, 10 (7\%) were misclassified as father present using the genealogical method-none were misclassified as father absent $(\mathrm{kappa}=.81)$. This method of determining father-absence status was sufficiently reliable for Bwa Mawego, given the pattern of conjugal relations there. The imputation of father absence may not be reliable in other populations for several reasons. Whenever possible, we strongly recommend cross-checking with multiple sources and types of data followed by formal analyses of reliability and validity.

Strictly speaking, this genealogical method provides an imperfect measure of father absence. However, father-absence status determined in the manner described is an adequate measure of conjugal stability-individuals who had several children with one mate ${ }^{3}$ had a more stable relationship than those who had only one child with one mate and then had other children with other mates. Number of mates with whom individuals had children is another obvious measure of conjugal stability. For consistency of analysis, we compared individuals who had children with only one mate to those who had children with more than one mate.

Separate analyses were conducted for males and females concerning the number of mates with whom individuals had children. Individuals with 
FIGURE 2

Most Children in the Village Have Been Raised in Father-Present Families

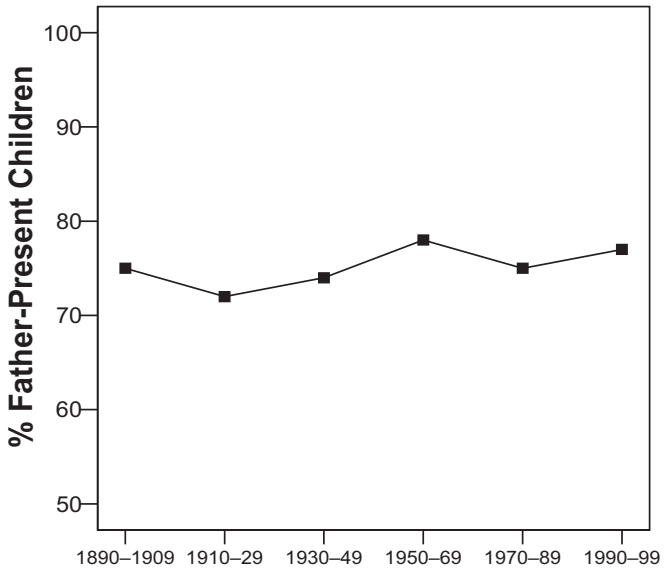

Birth Cohort

NOTE: Only about $30 \%$ of mothers are in long-term unions, but they have higher reproductive success than do "single" mothers (Quinlan 2001); hence, most children live in with two parents.

incomplete reproductive careers were excluded from these analyses. Agreement between mother-child father-absence status was analyzed separately from agreement between father-child father-absence status.

Results for father absence and conjugal stability. Father absence in early childhood has been a condition common to a significant minority of villagers for at least the last 100 years (average for all cohorts $=24 \%$ ). Furthermore, there is no cohort effect in the distribution of early father absence in this population (Figure 2). This indicates that factors contributing to conjugal instability have been relatively constant over the past century.

Initially, we conducted three tests of the Draper and Harpending (1982) model (see Quinlan and Flinn 2003; Quinlan and Quinlan 2007). First, we examined whether an individual's early family environment "predicted" their offspring's early family environment. Hence, we tested for an association between parents' father-absence status and offspring's father-absence status. Second, we were interested to see if individuals' early family environment was associated with later conjugal stability. Individuals whose mothers had 
offspring by more than one mate were predicted to themselves have offspring by more than one mate.

Women who spent their early years in a father-present household were slightly more likely to have father-present children than women who grew up in father-absent households. This effect is small, and the association is marginally significant $\left(x^{2}=2.09,1 d f, \phi=0.05\right.$, one-tailed $\left.p=.08, N=803\right)$. There was no association between offspring and father's father-absence status $\left(x^{2}=0.61,1 d f, \phi=-0.029\right.$, two-tailed $\left.p=.43, N=716\right)$. Women whose mothers had offspring by multiple mates were significantly more likely to have offspring by multiple mates than women whose mothers had offspring by only one man $\left(x^{2}=3.51,1 d f, \phi=0.14\right.$, one-tailed $p=.03, N$ $=188$ ). Men whose mothers had multiple mates were not more likely to have offspring with multiple mates than were men whose mothers had only one mate $\left(x^{2}=0.57,1 d f, \phi=0.06\right.$, one-tailed $\left.p=.22, N=193\right)$. Historically, it appears that over multiple generations, patterns of conjugal stability tend to be transmitted from mother to daughter but not from mother to son. None of the associations between fathers' conjugal stability and children's conjugal stability were significant.

\section{Education, Alcoholism, and Poverty}

We used genealogical interviews to study socioenvironmental hazards and opportunities in Bwa Mawego (Quinlan 2006). We used the genealogical database as a community roster, which allowed us to collect data for every young adult currently living in Bwa Mawego. Multiple logistic regression analyses presented here include eighty-seven men and fifty-six born between 1964 and 1986 (ages 18-40 in 2004) (Quinlan 2006). The upper age limit corresponds with the earliest reasonable availability of high school for rural Dominicans.

Many young people want to attend high school and leave the village to seek more opportunities and attractive lifestyles elsewhere. High school takes them outside the village for schooling and increases employability. Villagers are acutely aware, however, of the difficulties involved in obtaining an education. There are few opportunities for making a living in the village, and poverty is a defining feature of rural Dominican life. Heavy alcohol consumption is widespread among village men (Quinlan and Quinlan 2006).

Two separate groups of informants (discussed earlier) responded to questions about each villager 18 years and older concerning whether the individual had left the village, where he or she had resided, whether they had ever attended high school, whether he or she showed signs of alcoholism, 
and whether they were relatively poor compared with other villagers. The group interviews were also useful because the members could discuss each villager's situation and then come to a consensus on the best response, which was particularly helpful in determining whether an individual showed signs of alcoholism.

Some of the constructs were more difficult to pin down than others. Wording for high school attendance was straightforward, and interrater agreement between the two groups of informants was nearly perfect (kappa $\geq 0.90$ ). In contrast, the poverty construct required relatively extensive discussion. Our informants remarked that, with one or two exceptions, all of the villagers were poor. In the end, an impoverished person was defined as one "a little bit lower or below normal" for Bwa Mawego regarding possession of land, housing, household goods, or cash.

Classifying alcoholics depended on whether the individual was drinking plenty, usually several times per week (though he/she might have dry periods), and who regularly became intoxicated to the point of slurred speech and staggering. Drunken comportment is a rather significant feature of village life that occurs in public. Key informants and anthropologists had no difficulty agreeing on the classification of alcoholism. Our firsthand knowledge from long-term fieldwork (1993-present) and personal contact with many of the villagers classified as drinking plenty suggests that they show signs of alcohol dependence and/or frequent alcohol abuse as per the Diagnostic and Statistical Manual of Mental Disorders (American Psychiatric Association 1994). Interrater agreement for drinking plenty was high (kappa $=0.72)$.

The two groups showed acceptable agreement on all dichotomous measures $(k a p p a>0.70)$ except for poverty $(k a p p a=0.19)$. Cross-tabulation of responses shows that one group was reluctant to classify villagers as relatively poor. The discrepancy is not surprising considering the sensitive nature of wealth as a topic of discussion (see also Wilson 1973:81-82). As with many horticultural and peasant communities, people in Bwa Mawego attempt to conceal wealth and success to avoid jealousy and accusations of greediness (Wolf 1966; Edgerton 1971). The other group classified more villagers as impoverished; however, their dichotomous classification (impoverished/not impoverished) showed weak correlation with household inventories from a subsample of villagers in $1994(r=+.12)$. A three-category classification (poor/normal/well-off) showed better but still modest association with household inventories $(r=+.38)$. When the three-category classifications for both groups were averaged and split at the 75th percentile, then the association with the household inventories was considerably stronger $(r=+.60)$. The combined measure was used in the analyses below, but given questionable reliability, results for poverty should be interpreted with 
caution. Better measures of wealth such as land ownership are desirable and were subsequently collected (see below).

Multiple logistic regression modeled the probability of attending high school, alcoholism, and poverty as a function of year of birth (1964-1986) and sex $(1=$ male, $0=$ female $)$ to examine gender differences in outcomes. Outcome variables were coded as "1" for "attended high school," "alcoholic or drinking plenty," and "impoverished," or "0" for "did not attend high school," "not an alcoholic/drinking plenty," and "not impoverished." In a second analysis, men and women were analyzed separately to estimate associations between parental investment (PI) and gender-specific outcomes.

Three variables indicated PI: (1) Father present in the household ( $1=$ present, $0=$ absent) indicates the extent to which the father invests in the mother's children. Previous research in this community also shows that father presence substantially increases investment in children (Quinlan, Quinlan, and Flinn 2003) and women's RS (Quinlan 2001). Father presence, then, is a good proxy of PI and is correlated with mothers' number of offspring. (2) Father's number of mates measures the extent to which paternal resources may be divided among households. Number of mates refers to the number of women with whom a man had children and was calculated using the kin counter function in Descent. Men are expected to make some contribution to their nonresident children, but many men do not. (3) Mother's number of offspring (also calculated using the kin counter) measures the extent to which household resources are divided among siblings and was used rather than total number of siblings because many people had paternal half-siblings who lived in another household. Mother's RS is an imperfect proxy of PI because of potential phenotypic correlations: women with a coresident mate, more kin support, or wealth may be able to afford more children, and mother's RS by itself may not accurately reflect the absolute investment each child receives. Women's RS in Bwa Mawego is not significantly associated with wealth (Quinlan 2001; Quinlan and Flinn 2005), but it is positively associated with a coresident mate (Quinlan 2001) and the size of a woman's kin group (Quinlan and Flinn 2005). Size of mother's kin group residing in the village (minus offspring), calculated using Descent's relatedness function, was included as a control variable (along with father presence), making mother's number of offspring a better proxy of PI.

Results for education, alcoholism, and poverty. Controlling for year of birth, men were significantly less likely to attend high school than were women (odds ratio $[\mathrm{OR}]=0.19, p=.001$ ). Again controlling for year of birth, men were more likely to become impoverished $(\mathrm{OR}=2.01, p=.081)$, 
although the odds ratio was marginally significant. Men, however, were dramatically more likely to develop alcoholism than were women $(\mathrm{OR}=$ $11.13, p=.002$ ). These results show that boys have a higher probability of experiencing undesirable outcomes than girls and are less likely to benefit from the limited opportunities available to rural Dominicans. In general, men's outcomes were not associated with PI, as measured by childhood family environment (father's number of mates, mother's number of children, and father presence in the household), but women's outcomes except for high school attendance were associated with childhood family environment (Quinlan 2006).

\section{Kinship and Migration}

Rivers (1910) suggested that genealogies are useful for studying migration. After we had a complete genealogy going back at least 50 years, we found it quite easy to collect data on patterns of migration. Analyses presented here include 200 men and 220 women born in Bwa Mawego between 1953 and 1986 (Quinlan 2005). Migration status was determined through a series of interviews with multiple key informants in January, July, and August of 2004 and July of 2007, as discussed above.

Many villagers leave Bwa Mawego either temporarily or permanently (Quinlan 2005). Migration is a goal for many young people, who complain that there are too few jobs and educational opportunities in Dominica. Women say that jobless rural men are unattractive as mates, and men say that they cannot start a family without financial stability. Migration may be one means of improving educational, social, and reproductive opportunities, and it does appear to improve one's economic situation: many former villagers found good jobs and now live in the capital of Roseau. Presumably, remittances are important (see Olwig 1993:159-77), but such information is closely guarded.

Multiple logistic regression modeled migration from Bwa Mawego as a function of kin group characteristics. There were three analyses of criterion variables: whether the individual left (1) the village (migration), (2) the island (emigration), or (3) the village but not the island (internal migration). Predictor variables include the number of matrilateral and patrilateral kin living in the village (calculated with Descent's "lineage" function); number of brothers and sisters in the village (from the kin counter); whether a sibling had emigrated; presence of mother, father, mother's mother, mother's father, father's mother, and father's father in the village (all from the kin counter); a dichotomous variable indicating whether the immediate family is relatively poor compared with other villagers; year of birth; and sex (female $=0$, 
males $=1$ ). Finally, interaction terms for sex by first-order variables entered the model to examine gender-specific associations with migration.

Results for migration. Multiple logistic regression showed gender-specific kin effects on migration. Fifty-five percent of people born in Bwa Mawego between 1953 and 1986 have migrated; 33\% have left the island, and 22\% have migrated to other locations on Dominica. Men were less likely to leave than women-women had more than twice the odds of leaving the village $(\mathrm{OR}=2.09, p=.001)$. The size of the matrilateral kin group but not the patrilateral group was associated with the probability of migrating, which decreased as matrilateral group size increased ( $\mathrm{OR}=0.988, p=.043$ ). There was a significant sex-by-matrilateral-kin interaction, indicating that matrilateral kin had a stronger statistical effect on migration for women than for men $(\mathrm{OR}=1.024, p=.047)$. There was also a gender-specific effect of MM (mother's mother) on the probability of migration $(\mathrm{OR}=$ $4.47, p=.019)$ : women with an MM living in a village were less likely to leave than were other villagers. Year-of-birth-by-sex interaction was also significant $(\mathrm{OR}=0.941, \mathrm{p}=.044)$ : younger women were more likely to leave than were older women. Presence of the father in the village was associated with marginally greater odds of migrating $(p=.092)$, and number of sisters was associated with marginally lower odds $(\mathrm{p}=.054)$. Other relations were not significant. There were some differences between international and internal migration discussed in Quinlan (2005).

\section{Land Ownership}

Most recently, we used genealogical interviews to study land ownership. As is typical in horticultural or peasant communities, villagers in Bwa Mawego are very reluctant to talk openly about their wealth or land holdings, yet such information is common knowledge. For example, when RQ first began fieldwork in Bwa Mawego, our landlady's 12-year-old son became his cultural guide. As we walked along the village footpaths, without any prompt from RQ, he would name the owner of each fruit tree or patch of bwaden. He did this with some apparent pride in his ability. With adults, we could only talk about land in private, and quite often, those conversations ended in a rant about who was encroaching on their land or some other dispute. Clearly, a survey of land ownership would be very difficult.

Land is the foundation of economic production in Bwa Mawego. Bay oil extracted locally from bayleaf or bwaden trees (Pimenta racemosa L.) is the major source of cash coming into the village. Most villagers either own or work in bwaden for income. Land tenure in the village is complicated 
and sometimes contentious and has a pattern similar to other Caribbean populations (e.g., Clarke 1957). Rights to use family land in Bwa Mawego are transferred over generations to many descendants.

By custom, land cannot be partitioned or sold; however, the practice of usufruct allows improvements on land to be transferred to an individual. If one builds a house on family land, then that house can be sold. Similarly, if one plants trees on family land, then those trees can be sold or transferred to an individual. Bwaden is a relatively short tree that lives for many human generations; hence, ownership of bwaden can be passed on to one heir or can be sold, whereas the land itself cannot. This aspect of local usufruct allows us to estimate individual ownership of bwaden.

In the summer of 2006, Shane Macfarlan and RQ used the genealogical method to estimate ownership of bwaden patches. By then, our informants/ sources were well acquainted with the process of genealogical interviewing. We simply asked them to estimate the amount of bwaden each individual villager owns in acres, which is the local unit of land area. This was an easy and easygoing task for our sources. It was surprisingly easy for the informants to estimate acreage of bwaden: bwaden patches have boundaries clearly marked with red ti plants called malvina (Cordyline fruticosa (L.) A. Chev.), and the terrain is dissected so that one can observe people working in bwaden patches all around the village from many sites in the village.

Results for land ownership. Because land ownership is such a contentious issue in the community, we anticipated very low interrater reliability. In fact, we predicted that kinship between the source/informants and ego would explain interrater differences in bwaden ownership estimation.

The two sources (discussed above) estimated bwaden acreage for 155 common egos. One group estimated the average holding at .268 acre, with total bwaden acreage for the 155 egos at 41.7 acres. The other group estimated average holding at .263 acre, with total acreage for 155 egos at 40.8 acres. Initially, the interrater reliability for living villagers was a bit low but higher than anticipated (Pearson's $r=.55$; Cronbach's $\alpha=.68$ ). As we explored the kinship bias hypothesis, every test showed null results. This finding encouraged us to examine other sources of "error" between raters. The results revealed a somewhat unexpected pattern of land ownership when separate analyses of interrater reliability were conducted for men and women.

Reliability for men was quite high $(r=.70, \alpha=.79)$, indicating data that are reliable for further statistical analysis. Furthermore, estimates of bwaden ownership showed "convergent validity": acres of bwaden owned was positively associated with men's completed RS ( $r=.30, p=.02, n=$ 61 ), which is consistent with findings for land ownership and men's RS on 
Trinidad (Flinn 1986). In contrast, reliability for women's bwaden ownership was very low $(r=.18, \alpha=.29)$. Interestingly, the raters agreed on the men's bwaden ownership, and they agreed on the total amount of land under bwaden cultivation; however, they showed substantial disagreement on women's ownership. This finding offers empirical evidence that female land rights are not nearly as clear cut as are men's rights. The finding did not emerge from over a decade of informal qualitative interviews on the subject of land rights. Apparently, everyone in Bwa Mawego agrees that women can own and inherit bwaden (see also Clarke 1957 for rural Jamaica), but the situation seems more contentious for women than for men when it comes to recognizing individual land rights. This finding suggests an important avenue for future research.

\section{DISCUSSION}

Along with participant observation, genealogical interviewing has been one of the mainstays of ethnographic fieldwork for over 100 years. There is, however, very little written about how to collect genealogies and less about what to do with them. We have outlined an iterative computer-assisted method for collecting accurate genealogies. Furthermore, we have presented several examples of how genealogical data can be analyzed and how the process of genealogical interviewing can be extended to study other aspects of a population, including health, education, land ownership, migration, and so forth. Recently, we have also begun using the genealogical interview format to collect "peer ratings" on standardized personality inventories.

Genealogical interviewing is particularly useful in face-to-face, kin-based communities where prevailing cultural models are not conducive to questionnaire-driven surveys. Geographically dispersed populations organized into small settlements scattered over a large area might present some special challenges, especially regarding the boundaries of emically recognized communities. Then, the structure of relatedness in a region might create a kind of clinal distribution so that the emic community includes many thousands of interrelated individuals. This may be the case in some large African pastoralist groups such as the Herero (Pennington and Harpending 1993). In that case, the ethnographer might do well to choose a focal settlement or cluster of settlements and construct the genealogy around that unit. In such a case, it would be particularly important to pay close attention to patterns of exogamy. Finally, the method is probably inappropriate in most urban industrial societies and in migrant communities where the settlement pattern is not based on long-term affiliations among households. 
Constructing the initial genealogy can be time consuming, but the payoff comes in having a large, easily comparable and broadly useful data set for further ethnographic research. The genealogical interview itself is not entirely mechanical, so fieldworkers and informants can and often do explore many issues that arise in the context of genealogical interviewing. The methods proposed here are well suited for multitasking in fieldwork. RQ was almost always working on other fieldwork activities (e.g., direct systematic observation, participant observation, anthropometry) while developing the genealogical database. He was able to make good progress on these genealogical data by periodically allocating 10-12 hours per week to them while in the field. Researchers, however, must decide for themselves whether these genealogical methods (or any particular methods) are worth the effort. We suggest that most population studies of small-scale communities would benefit from the approach outlined here. Finally, the method requires at least two independent sources to assess data reliability.

In sum, genealogies and genealogical interviewing are broadly valuable for anthropological and related research. These quantitative data are reliable and valid. The approach is unobtrusive and well suited to ethnographic field research. These methods deserve much more attention.

\section{NOTES}

1. Data are from the U.S. Census Bureau, http://www.census.gov/ipc/www/idb/ (accessed January 18, 2008).

2. Given the relatively small samples anthropologists typically analyze and the rich contextual data available for cross-checking results, we suggest that anthropologists would be wise to examine marginally significant results $(p \leq .10)$ closely. Such effects might suggest refined analyses, better measures, and important avenues for qualitative research. Simply declaring such results nonsignificant based on a small, arbitrary difference in $p$ value is not an efficient or sensible use of data.

3. Here, we use the term mate because marriages are rather rare in Bwa Mawego. Other local words capture the sexual nature of the relationship, such as stepni, which roughly translates as boyfriend/girlfriend or lover. However, by mate, we mean a reproductive relationship that goes beyond stepni but does not necessarily include marriage. In fact, some "visiting" relationships (a term not locally recognized in this context) might not even qualify as stepni, even when the couple may have a child as a result of the relationship.

\section{REFERENCES}

American Psychiatric Association. 1994. Diagnostic and statistical manual of mental disorders, 4th ed. Arlington, VA: Author. 
Barnard, A., and A. Good. 1984. Research practices in the study of kinship. New York: Academic Press.

Barnes, J. A. 1967. Genealogies. In Craft of social anthropology, edited by A. L. Epstein, 101-27. New York: Tavistock.

Bernard, H. R. 1998. Handbook of methods in cultural anthropology. Walnut Creek, CA: AltaMira. 2002. Research methods in anthropology: Qualitative and quantitative approaches, 3rd ed. Walnut Creek, CA: AltaMira.

Bohannan, L. 1952. Genealogical charter. Africa 22 (4): 301-15.

Chagnon, N. A. 1974. Studying the Yanomamo. New York: Holt, Rinehart \& Winston.

. 1979. Mate competition, favoring close kin, and village fissioning among the Yanomamo Indians. In Evolutionary biology and human social behavior: An anthropological perspective, edited by N. A. Chagnon and W. Irons, 86-132. Northe Scituate, MA: Duxbury.

. 2000. Manipulating kinship rules: A form of male Yanomamo reproductive competition. In Adaptation and human behavior: An anthropological perspective, edited by L. Cronk, N. A. Chagnon, and W. Irons, 115-32. New York: Aldine DeGruyter.

Chagnon, N. A., and J. Bryant. 1984. KINDEMCOM: The fourth style in the study of human kinship. Unpublished manuscript, University of California at Santa Barbara.

Clarke, E. 1957. My mother who fathered me: A study of the family in three selected communities in Jamaica. London: Allen and Unwin.

Cronk, L. 2004. From Mukogodo to Maasai: Ethnicity and cultural change in Kenya. Cambridge, MA: Westview.

de Munck, V. G., and E. J. Sobo. 1998. Using methods in the field: A practical introduction and casebook. Walnut Creek, CA: AltaMira.

Draper, P., and H. Harpending. 1982. Father absence and reproductive strategy: An evolutionary perspective. Journal of Anthropological Research 38 (3): 255-79.

DuMont, L. 1953. The Dravidian kinship terminology as an expression of marriage. Man 53:34-39.

Edgerton, R. 1971. The individual in cultural adaptation: A study of four East African peoples. Berkeley: University of California Press.

Flinn, M. V. 1986. Correlates of reproductive success in a Caribbean village. Human Ecology 14 (2): 225-43.

Flinn, M. V., D. Leone, and R. J. Quinlan. 1999. Growth and fluctuating asymmetry of stepchildren. Evolution and Human Behavior 20 (6): 465-79.

Goodenough, W. 1955. Residence rules. Southwestern Journal of Anthropology 12 (1): 22-37. 1967 Componential analysis. Science 156 (3779): 1203-9.

Hagen, E. n.d. Descent [computer software]. http://code.google.com/p/descent/ (accessed January 10, 2008).

Hammel, E. A. 1976. The matrilateral implications of structural cross-cousin marriage. In Demographic anthropology: Quantitative approaches, edited by E. B. W. Zubrow, 145-68. Albuquerque: University of New Mexico Press.

Olwig, K. F. 1993. Global culture, island identity: Continuity and change in the Afro-Caribbean community of Nevis. Philadelphia: Harwood.

Pennington, R., and H. Harpending. 1993. Structure of an African pastoralist community: The demography, history, and ecology of the Ngamiland Herero. Oxford, UK: Oxford University Press.

Quinlan, M. B., and R. J. Quinlan. 2006. Alcoholism in a Caribbean community: Ethnography, epidemiology and evolutionary ecology. Paper presented at the 66th annual meeting of the Society for Applied Anthropology, Vancouver, Canada, March 28-April 2. 
Quinlan, R. J. 2001. Effect of household structure on female reproductive strategies in a Caribbean community. Human Nature 12 (3): 169-89.

- 2005. Kinship and migration from rural Dominica. Migration Letters 2 (1): 2-12.

. 2006. Gender and risk in a matrifocal Caribbean community. American Anthropologist 108 (3): 469-79.

Quinlan, R. J., and M. V. Flinn. 2003. Intergenerational transmission of conjugal stability in a Caribbean village. Journal of Comparative Family Studies 34 (4): 569-83.

2005. Kinship, sex and fitness in a Caribbean community. Human Nature 16 (1): 32-57.

Quinlan, R. J., and M. B. Quinlan. 2007. Parenting and cultures of risk: A comparative analysis of infidelity, aggression and witchcraft. American Anthropologist 109 (1): 164-79.

Quinlan R. J., M. B. Quinlan, and M. V. Flinn. 2003. Parental investment and age at weaning in a Caribbean village. Evolution and Human Behavior 24 (1): 1-16.

Rivers, W. H. R. 1900. A genealogical method of collecting social and vital statistics. Journal of the Royal Anthropological Institute of Great Britain and Ireland 30:74-82.

- 1910. The genealogical method of anthropological inquiry. Sociological Review 3 (1): $1-12$.

Riviere, P. 1969. Marriage among the Trio. Oxford, UK: Clarendon.

Roberts, P. A. 1988. West Indians and their language. Cambridge, UK: Cambridge University Press.

Romney, A. K., and P. J. Epling. 1958. A simplified model of Kariera kinship. American Anthropologist 60 (1): 59-74.

Roopnarine, J. L., R. Singh, P. Bynoe, and R. Simon. 2005. Caribbean families in Englishspeaking countries: A rather complex mosaic. In Families in global perspective, edited by J. L. Roopnarine and U. P. Gielen, 311-29. Boston: Pearson.

Schneider, D. M., and G. C. Homans. 1955. Kinship terminology and the American kinship system. American Anthropologist 57 (6): 1194-208.

Schusky, E. L. 1983. Manual for kinship analysis, 2nd ed. New York: University Press of America.

Smith, R. T. 1996. The matrifocal family. New York: Routledge.

Wilson, P. J. 1973. Crab antics: The social anthropology of English-speaking Negro societies of the Caribbean. New Haven, CT: Yale University Press.

Wolf, E. 1966. Peasants. Englewood Cliffs, NJ: Prentice-Hall.

ROBERT J. QUINLAN is an assistant professor of evolutionary and cultural anthropology at Washington State University, Pullman. His main interests include family, kinship, life history, and psychosocial development. He has a dual research program, including cross-cultural analysis and a long-term ethnographic study in the Commonwealth of Dominica. He recently published several studies on the effects of environmental risk on parenting and ideational culture (http://www.wsu.edu/ rquinlan/).

EDWARD H. HAGEN is an assistant professor of evolutionary anthropology at Washington State University, Pullman. His main interests include evolutionary medical anthropology; evolutionary psychology; evolutionary approaches to emotions, mental health, and addiction; life history approaches to child nutrition and development; and biocultural perspectives on parental investment. 